$\left(\begin{array}{ccc}\text { Jpn. J. Hosp. Pharm. } \\ \text { 24(4) } & 389-392(1998)\end{array}\right)$

\title{
Particulate Matter Analyses after Dissolution of Powder Antibiotic Injections Used in the Pediatric Ward
}

\author{
MASAAKI HIRAKAWA, TOSHIAKI SENDO, YASUFUMI KATAOKA, \\ SAORI IMAFUKU ${ }^{\text {a) }}$, KOUJIRO FUTAGAMI ${ }^{\text {b) }}$ and RYOZO OISHI* \\ Department of Hospital Pharmacy, Faculty of Medicine, Kyushu University $\dagger$
}

\author{
$\left(\begin{array}{lc}\text { Received August 27, } & 1997 \\ \text { Accepted February 23, } & 1998\end{array}\right)$
}

Final filters have not been always used for injections in the pediatric ward of our hospital. Since thore has been no report on the particulate matters of five dissolved antibiotics in vial, we measured those amounts using a particle counter. The amounts of particulate matters in the solutions of cefpirome sulfate, flomoxef sodium and panipenem/betamipron were below the limits defined by the Japanese Pharmacopoeial Forum(1996) or United States Pharmacopoeia (USP XXIII). However, particles above $10 \mu \mathrm{m}$ in imipenem/cilastatin sodium and vancomycin hydrochloride immediately after dissolution were about $70 \%$ of the limit. Scanning electron micrographs of the filter membrane surface showed the existence of insoluble particulate contaminants in those injections. Final filters are recommended for these antibiotic injections to be used safely in pediatric patients.

Key words - particulate matter, imipenem/cilastatin sodium, vancomycin hydrochloride, scanning electron microscopy, X-ray emission spectrometry

\section{Introduction}

Final filters are useful for minimizing the problems of intravenous injections including particulate matters, and are used especially for the infusion to immature infants. The use of final filter was limited to the patients who received the total parenteral nutrition or showed the white blood cell count less than $500 / \mu \mathrm{L}$, in the pediatric ward of our hospital. However, it is not clear whether the final filter is always needed for any injections. In addition, dissolved injections are often used repeatedly by splitting in the pediatric ward. There have been many reports on particulate matter in small volume antibiotic injections ${ }^{1-6)}$. However, we could obtain no information of particulate matter in five out of thirteen antibiotic injections used in the pediatric ward of our hospital. Thus, we measured particulate matters in these five antibiotic injections after dissolution to clarify whether final filters are necessary.

†福岡市東区馬出3-1-1;3-1-1, Maidashi, Higashi-ku, Fukuoka, 812-0054 Japan

a) 現 : 国立療養所大牟田病院薬殽部; Omuta National Hospital, Pharmacy

b) 現 : 岡山大学医学部附属病院薬剤部; Department of Hospital Pharmacy, Okayama University Medical School 


\section{Materials and Methods}

The antibiotic injections were dissolved in the solution commonly used in the pediatric ward. Cefpirome sulfate (Broact $^{\circledR}, 251$ D 125, shionogi, Osaka, Japan), flomoxef sodium (Flumarin ${ }^{\circledR}$, 5001, Shionogi), and panipenem/betamipron (Carbenin ${ }^{\circledR}$, W 090 H, Sankyo, Tokyo, Japan) were dissolved in $5 \%$ glucose injections $(10 \mathrm{~mL})$. Vancomycin hydrochloride (Vancomycin ${ }^{\circledR}, 5029$, Shionogi), and imipenem/cilastatin sodium (Tienam ${ }^{\circledR}, 6 \mathrm{~A} 444 \mathrm{P}$, Banyu, Tokyo) were dissolved in sterile water for injection $(10 \mathrm{~mL})$ and $0.9 \%$ sodium chloride injections $(100 \mathrm{~mL})$, respectively. Three vials of each antibiotic solution were stored at $4^{\circ} \mathrm{C}$ for up to $48 \mathrm{~h}$ after dissolution. The sample was shaken vigorously for $10 \mathrm{sec}$ and confirmed to be clear.

Ultra pure water prepared in a Milli-Q Reagent Water System (Millipore, Tokyo) and passed through a Millipore $0.22 \mu \mathrm{m}$ cartridge filter was used for reconstitution and rinsing. The preparation of antibiotic solutions for the counting of particulate matters was performed in a clean bench (model AH-160, Astec Ltd., Fukuoka, Japan). After $3 \mathrm{~mL}$ of each sample solution was mixed with $47 \mathrm{~mL}$ of ultra pure water, the particulate content was assessed by the Automatic Parenteral Sampling System (APSS) (Particle Measuring System, Boulder, Colo., USA). The sensor was rinsed with particle-free water before each measurement. The APSS consisted of an information display system (IBM compatible computer), Liquid Sampler-200 (LS-200) and Liquilaz-E 20 (light obscuration sensor). The measurement conditions of the APSS were as follows : sample volume, $5 \mathrm{~mL}$; tare volume, $1 \mathrm{~mL}$; fill speed, $20 \mathrm{~mL} / \mathrm{min}$; drain speed, $50 \mathrm{~mL} / \mathrm{min}$; number of, samples, 4 ; the first sample was discarded. Particulate matter in the size range of $2.0 \mu \mathrm{m}$ to $100 \mu \mathrm{m}$ were measured.

Imipenem/cilastatin sodium and vancomycin hydrochloride, both being clarified to include considerable amounts of particulate matter, were filtered through $0.45 \mu \mathrm{m}$ membranes (HA type, Millipore) immediately after dissolution, and the membrane filter was observed under a scanning electron microscope. The membranes were carefully removed from the filter housing, gently rinsed with double distilled water and dried using a petrislide. The sample was fixed on an aluminum stub $(1 \times 1 \mathrm{~cm})$ with double-sided adhesive tape and carbon coated in a Hitachi $5 \mathrm{~GB}$ high vacuum evaporator on a tilting rotary turntable (30 A and $1 \times 10^{-6}$ Torr). The sample was imaged at $25 \mathrm{keV}$ using a Hitachi S-510 scanning electron microscope. The X-ray fluorescence of the individual particle was recorded using an X-ray emission spectrometry (model EMAX-1770, Horiba Ltd., Kyoto, Japan).

\section{Results and Discussion}

Table 1 shows the amounts of particulate matters in five antibiotic injections up to $48 \mathrm{~h}$ after dissolution. The limits for particulate matters in small volume injections defined in the JP Forum and USP are 6,000 and 600 pieces per container for particles more than 10 and $25 \mu \mathrm{m}$, respectively. Injection solutions of cefpirome sulfate, flomoxef sodium and panipenem/betamipron showed the particle counts less than $10 \%$ of the limit. The counts of particles above $10 \mu \mathrm{m}$ in imipenem/ cilastatin sodium and vancomycin hydrochloride injections were about $70 \%$ of the USP limit immediately after dissolution. The particles above $25 \mu \mathrm{m}$ were less than $10 \%$ /of the limit. Other antibiotic injections used in the pediatric ward (ampicillin sodium, aztreonam, cefazolin sodium, cef- 
Table 1. Particulate Matter Count in Five Antibiotic Solutions

\begin{tabular}{|c|c|c|c|c|c|}
\hline \multirow[b]{2}{*}{ Drug and content per vial } & \multicolumn{5}{|c|}{ Pieces per container $\geq 10 \mu \mathrm{m}$} \\
\hline & Immediately & $1 \mathrm{~h}$ & $6 \mathrm{~h}$ & $24 \mathrm{~h}$ & $48 \mathrm{~h}$ \\
\hline Cefpirome sulfate $1 \mathrm{~g}$ & $356 \pm 266$ & & & $332 \pm 273$ & $74 \pm 43$ \\
\hline Flomoxef sodium $1 \mathrm{~g}$ & $128 \pm 84$ & & & $306 \pm 215$ & $94 \pm 40$ \\
\hline Imipenem/Cilastatin sodium $0.5 \mathrm{~g}$ & $4278 \pm 759$ & $3537 \pm 1002$ & $2148 \pm 210$ & $1574 \pm 357$ & $741 \pm 335$ \\
\hline Panipenem/Betamipron 0.5g & $263 \pm 81$ & & & $363 \pm 114$ & $120 \pm 42$ \\
\hline Vancomycin hydrochloride $0.5 \mathrm{~g}$ & $4294 \pm 899$ & $3044 \pm 389$ & $2539 \pm 418$ & $744 \pm 135$ & $230 \pm 66$ \\
\hline
\end{tabular}

Mean \pm S.D. of three samples.
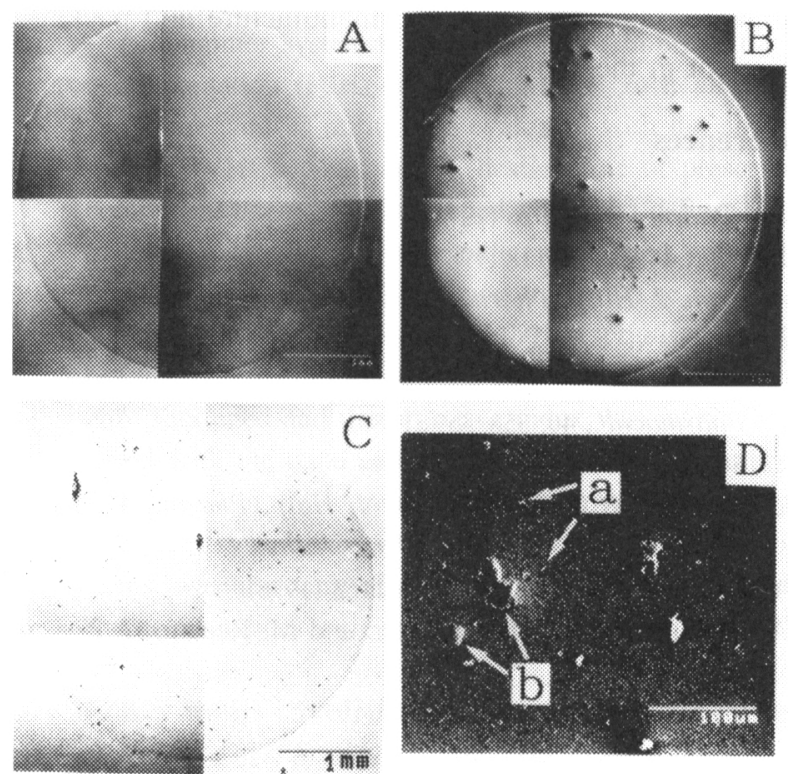

Fig. 1.
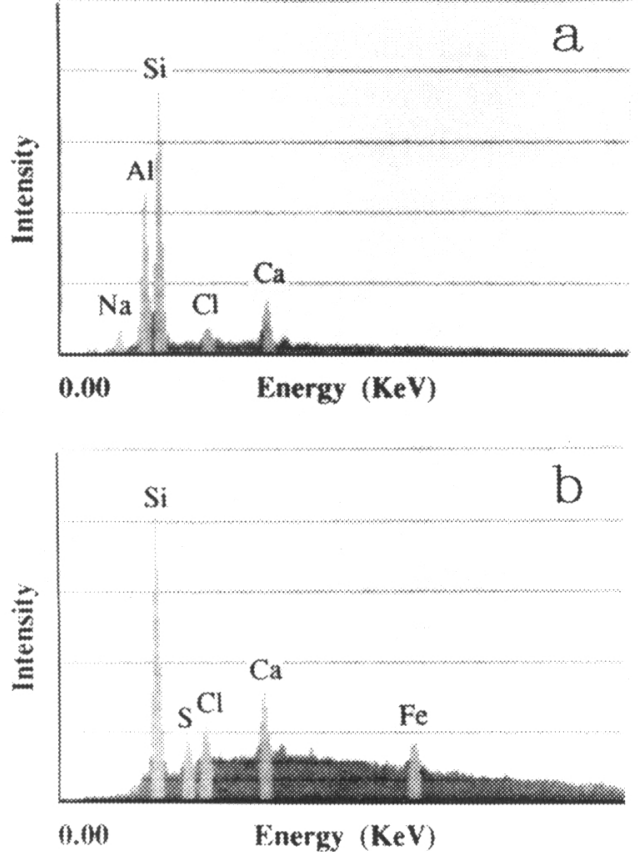

Fig. 2.

metazole sodium, cefotaxime sodium, cefotiam hydrochloride, ceftazidime and piperacillin sodium) showed particle counts less than $10 \%$ of the limit (date not shown) in good agreement with previous reports ${ }^{1-6)}$. Fig. 1 shows the membrane surface by scanning electron microscopy after filtration of imipenem/cilastatin sodium (C and D) and vancomycin hydrochloride solutions (B). Fig. 2 sho- 
ws two typical examples of X-ray spectrogram for the particulate contaminant (D) in imipenem/ cilastatin sodium solution. The X-ray emission spectrometry of particles on scanning electron micrographs detected various inorganic elements notably aluminum, silicon, sulfur and iron.

This is the frst report on the particulate matters in the imipenem/cilastatin sodium and vancomycin hydrochloride injections in the clinical setting, and this may be useful for the proper use of these injections. There is increasing evidence that particulate matters in parenteral solutions may induce harmful reactions such as inflammation and embolism ${ }^{7-9)}$. However, final filters are not always used for injections, because those are expensive and not covered by medical insurance in Japan. The present results suggest that final filters may be important to protect against unexpected harmful influence, when imipenem/cilastatin sodium and vancomycin hydrochloride are injected to pediatric patients. Especially, final filters should be used in polypharmacy or bolus therapy. The present results also suggest that final filters are of less importance for other eleven antibiotic injections described above.

In the former study, the particulate matter in some large volume parenteral container was reported to increase up to six days after dissolution and decrease precipitously over seven days ${ }^{10)}$. However, both particulate matter in imipenem/cilastatin sodium and vancomycin hydrochloride were gradually decreased up to $48 \mathrm{~h}$ after dissolution, suggesting that the complex including these antibiotics and inorganic elements becomes smaller gradually. The results from the X-ray emission spectrometry of particles suggest an involvement of contamination in the manufacture and packaging procedures. There may be room for improvement in these procedures.

\section{References}

1) J.Y. Masuda and J.H. Beckerman, Am. J. Hosp. Pharm., 30, 72-76 (1973).

2) D.A. Parkins and A.J. Taylor, Am. J. Hosp. Pharm., 44, 1111-1118 (1987).

3) H.J. Mioduch, A.D. Czaplicki, and B.G. Schulz, Am. J. Hosp. Pharm., 40, 1982-1983 (1983).

4) C.M. Backhouse, P.R. Ball, S. Booth, M.A. Kelshaw, S.R. Potter, and C.N. McCollum, J. Pharm. Pharmacol., 39, 241-245 (1987).

5) D.M. Alexander and A.M. Veltman, J. Pharm. Pharmacol ., 40, 358-359 (1988).

6) M. Niizeki and K. Tanno, Jpn. J. Antibiot., 42, 567-572 (1989).

7) P.P DeLuca, R.P. Rapp, B. Bivins, H.E. McKean, and W.O. Griffen, Am. J. Hosp. Pharm., 32, 10011007 (1975).

8) W.E. Evans, L.F. Barker, and J.V. Simone, Am. J. Hosp. Pharm., 33, 1160-1163 (1976).

9) M.A. Rodriguez, M.C. Martinez, M. Lopez-Artiguez, M.L. Soria, F. Bernier, and M. Repetto, J. Forensic Sci., 34, 504-510 (1989).

10) R.J. Whitlow, T.E. Needham, and L.A. Luzzi, J. Pharm. Sci., 63, 1610-1613 (1974). 